Virginia Commonwealth University

vCU Scholars Compass

1984

\title{
Magnetic and Mössbauer study of metal-zeolite interaction in catalysts
}

Thomas Pannaparayil

Pennsylvania State University

M. Oskooie-Tabrizi

Pennsylvania State University

C. Lo

Pennsylvania State University

See next page for additional authors

Follow this and additional works at: http://scholarscompass.vcu.edu/chem_pubs

Part of the Chemistry Commons

Pannaparayil, T., Oskooie-Tabrizi, M., Lo, C., et al. Magnetic and Mössbauer study of metal-zeolite interaction in catalysts. Journal of Applied Physics 55, 2601 (1984). Copyright (C) 1984 AIP Publishing LLC.

\section{Downloaded from}

http://scholarscompass.vcu.edu/chem_pubs/42

This Article is brought to you for free and open access by the Dept. of Chemistry at VCU Scholars Compass. It has been accepted for inclusion in Chemistry Publications by an authorized administrator of VCU Scholars Compass. For more information, please contact libcompass@vcu.edu. 
Authors

Thomas Pannaparayil, M. Oskooie-Tabrizi, C. Lo, L. N. Mulay, G. A. Melson, and V. U. S. Rao 


\title{
Magnetic and Mössbauer study of metal-zeolite interaction in catalysts
}

Thomas Pannaparayil

Physics Department, Pennsylvania State University, Sharon, Pennsylvania 16156

M. Oskooie-Tabrizi, C. Lo, and L. N. Mulaya)

Materials Science and Engineering Department, Pennsylvania State University, University Park, Pennsyluania 16802

G. A. Melson

Chemistry Department, Virginia Commonwealth University, Richmond, Virginia 23284

V. U.S. Rao

Pittsburgh Energy Technology Center, U.S. Department of Energy, Pittsburgh, Pennsylvania 15236

\begin{abstract}
Molecular sieve aluminosilicates, such as ZSM-5 and mordenite, when impregnated with highly dispersed $\mathrm{Fe}$, yield catalysts for the selective conversion of coal-derived syngas $\left(\mathrm{CO}+\mathrm{H}_{2}\right)$ to liquid hydrocarbon fuels. Fe performs the primary Fischer-Tropsch (FT) syngas to yield light olefins which are converted by the acidic $\left(\mathrm{H}^{+}\right)$and shape-selective function of the zeolite to high octane gasoline components. The physical aspects of the Fe-mordenite interaction studied by magnetic measurements, Mössbauer, and IR spectroscopy are reported and correlations with the catalytic properties are drawn. Mordenite samples with $\left[\mathrm{SiO}_{2} / \mathrm{Al}_{2} \mathrm{O}_{3}\right]$ ratio in the range $12-60$ were impregnated with 15 wt. \% Fe using $\mathrm{Fe}_{3}(\mathrm{CO})_{12}$; decarbonylation yielded superparamagmetic dispersions of $\gamma-\mathrm{Fe}_{2} \mathrm{O}_{3}$, in the range $1.4-5.0 \mathrm{~nm}$; the smallest particles were obtained for a ratio $=17$. Hydrogen chemisorption also revealed a similar trend in Fe dispersions. No samples, other than the one with a ratio $=60$ and containing the largest particles could be carbided under usual conditions. The acidity of the mordenite and the aromatics fraction in liquid hydrocarbons from syngas conversion also showed maxima at a ratio $=17$. The presence of a strong metal-support interaction between $\mathrm{Fe}$ and mordenite was thus influenced by the varying ratios in the mordenite in a manner that paralleled the acidity and catalytic activity.
\end{abstract}

PACS numbers: $70.50 . \mathrm{Bb}, 76.80 .+\mathrm{y}, 82.65 . \mathrm{Jv}, 89.30 .+\mathrm{f}$

\section{INTRODUCTION}

Mössbauer and magnetic studies are becoming increasingly important in the characterization of catalysts, ${ }^{1}$ particularly used in coal liquefaction. ${ }^{2}$ In recent years zeolitebased catalysts have found application in the conversion of syngas $\left(\mathrm{CO}+\mathrm{H}_{2}\right)$ to hydrocarbon fuel ${ }^{3-6}$ of the high octane gasoline type.

The conversion of $\mathrm{CO}+\mathrm{H}_{2}$ in one step to a mixture of hydrocarbon species which constitute high octane range gasoline appears possible with catalysts such as ZSM-5 and a group VIII metal. ${ }^{2-5}$ The influence of metal-zeolite interaction on metal cluster size and product selectivity is of considerable interest. In the present study mordenite was chosen as the zeolite since it can be synthesized over a wide range of $\mathrm{SiO}_{2} / \mathrm{Al}_{2} \mathrm{O}_{3}$ mole ratios and its acidity has been characterized. ${ }^{7,8}$ The catalytic activity and acidity (number and strength of the Brönsted or $\mathrm{H}^{+}$sites) were found to exhibit maxima at a ratio of $\left[\mathrm{SiO}_{2} / \mathrm{Al}_{2} \mathrm{O}_{3}\right]=17$. Hence, it was important in this study to examine if parameters associated with metal cluster size and the Fe-mordenite interaction show a parallel trend as a function of the above ratio in mordenites.

The mordenite samples, impregnated with $\mathrm{Fe}$ using $\mathrm{Fe}_{3}(\mathrm{CO})_{12}$, have been examined by Mössbauer and IR spectroscopy and magnetization measurements. This information is correlated with $\mathrm{H}_{2}$ chemisorption, syngas conversion

\footnotetext{
a) Work supported in part by DOE contract number DE-AC22-81PC41266. Address enquiries to this author (LNM).
}

activity, and previous activity measurements to explore the possibility of metal-zeolite interaction in these systems. The influence of metal-support interactions on chemisorptive and catalytic properties has attracted much attention in recent years. ${ }^{9}$ In some cases the interactions have been classified ${ }^{9}$ as either weak (e.g., with $\mathrm{SiO}_{2}$ and $\mathrm{Al}_{2} \mathrm{O}_{3}$ ), medium (with zeolites) or strong (e.g., with $\mathrm{TiO}_{2}$ ). The possible influence of such effects in syngas conversion over metal-zeolite (mordenite) catalysts has not yet been investigated systematically. In an earlier paper, Mulay and co-workers ${ }^{10}$ showed from exploratory Mössbauer measurements that the isomer shift $\delta$ showed a maxima at a critical ratio $=17$ in $\mathrm{H}$-mordenites. A diagram for $\mathbf{H}$-mordenite is also given in the previous paper. ${ }^{10}$ The present paper provides an outline of a similar investigation in the $\mathrm{Fe}$-mordenite system.

\section{EXPERIMENT}

The samples of $\mathrm{H}$-mordenite in the acid form $\left[\mathrm{H}_{8} \mathrm{Al}_{8} \mathrm{Si}_{40} \mathrm{O}_{96}\right] \cdot 24 \mathrm{H}_{2} \mathrm{O}$ with $\mathrm{H}^{+}$as the cation, were obtained from the Norton Company. The $\mathrm{H}$-mordenite samples with ratios $\left[\mathrm{SiO}_{2} / \mathrm{Al}_{2} \mathrm{O}_{3}\right]=12,17,20$, and 60 , respectively, were studied; these are referred to as A, B, C, and D, respectively. The calcined $\mathrm{H}$-mordenite samples were impregnated with approximately $15 \mathrm{wt}$. \% Fe with $\mathrm{Fe}_{3}(\mathrm{CO})_{12}$, using cyclohexane as the extraction solvent. ${ }^{11}$ The $\sigma$ measurements, as a function of $H$ and $T$, on the catalysts were carried out with a Vibrating Sample Magnetometer and a Faraday microbalance. ${ }^{12,13} \mathrm{~A}$ brief description of the Mössbauer spectrometer is given elsewhere. ${ }^{2}$ 
The in situ magnetic and the Mössbauer measurements were performed on the samples at various stages; namely, (a) after impregnation with $\mathrm{Fe}_{3}(\mathrm{CO})_{12}$; (b) on reduction in $\mathrm{H}_{2}$ at $450^{\circ} \mathrm{C}$ for $16 \mathrm{~h}$; (c) on carbiding in syngas $\left(1: 1 \mathrm{H}_{2} / \mathrm{CO}\right)$ at $250{ }^{\circ} \mathrm{C}$ for $16 \mathrm{~h}$; and (d) finally at the end of the syngas conversion to gasoline range hydrocarbons. The catalytic activity of the samples for the conversion of syngas was determined after reduction in flowing $\mathrm{H}_{2}$ at $450^{\circ} \mathrm{C}$ using a fixed bed microreactor in conjunction with a conventional gas chromatograph. ${ }^{11}$ Prior to catalytic activity tests, IR spectra of the samples were also recorded.

\section{RESULTS AND DISCUSSION}

The IR spectra obtained on the as-prepared catalysts showed no evidence for the presence of carbonyl bands. Predominantly $\mathrm{O} \leftrightarrow \mathrm{H}$ stretching bands $\left(3653 \mathrm{~cm}^{-1}\right)$ were observed, which also showed a maximum intensity at a ratio $=17$. This suggested that decarbonylation of $\mathrm{Fe}_{3}(\mathrm{CO})_{12}$ had taken place on the $\mathrm{H}$-mordenite support during the impregnation. The $\mathrm{x}$-ray powder diffraction patterns indicated the presence of $\gamma-\mathrm{Fe}_{2} \mathrm{O}_{3}$, in addition to the expected reflections from the $\mathrm{H}$-mordenite phase.

Magnetization $\sigma$ plotted as a function of $H / T$ is shown in Fig. 1. The data points obtained over the cryogenic range ( 78 and $300 \mathrm{~K}$ ) and $H$ up to $20 \mathrm{kOe}$ showed good superposition. Thus, superparamagnetic behavior was found in all cases. The average cluster size of $\gamma-\mathrm{Fe}_{2} \mathrm{O}_{3}$ was calculated ${ }^{\prime \prime}$ from Fig. 1 using the low and high field approximation of the Langevin function. ${ }^{12}$ The cluster sizes obtained are shown as a function of the ratio in Fig. 2. For comparison, the cluster sizes of Fe measured by $\mathrm{CO}$ chemisorption, after reducing the samples in flowing $\mathrm{H}_{2}$ at $450^{\circ} \mathrm{C}$, are also shown in Fig. 2 .

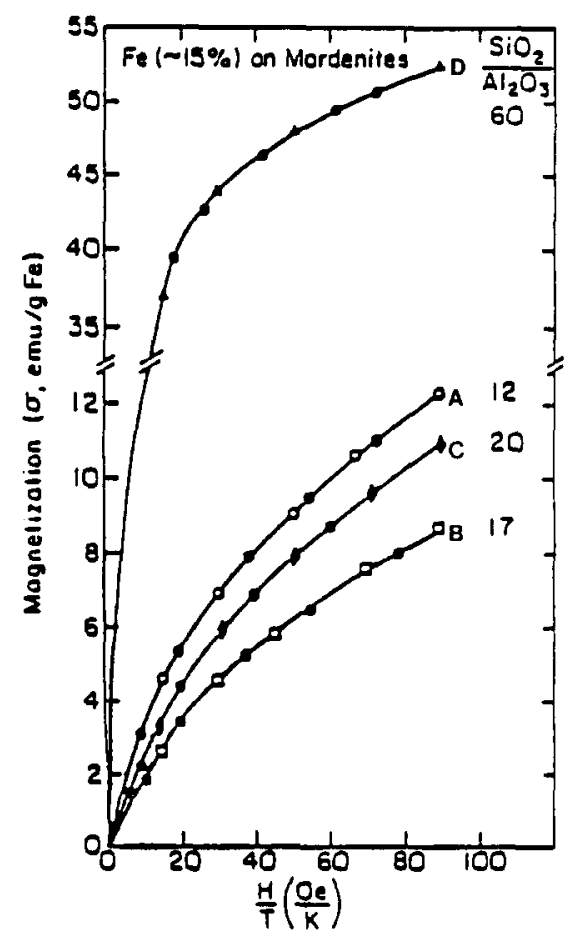

FIG. 1. Magnetization as a function of $H / T$ for Fe on mordenites with varying $\mathrm{SiO}_{2} / \mathrm{Al}_{2} \mathrm{O}_{3}$ ratio.

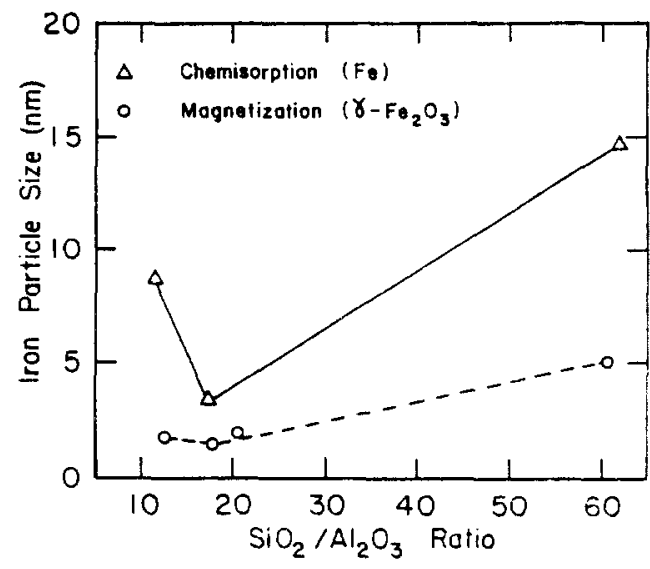

FIG. 2. Estimated crystallite size of the Fe-containing phase in Fe-mordenite catalysts from $\mathrm{CO}$ chemisorption and magnetization.

The particle size versus the ratios showed a similar trend in the two cases. The larger $\mathrm{Fe}$ cluster size obtained from $\mathrm{H}_{2}$ chemisorption may be attributed to sintering of the clusters, during the reduction of $\gamma-\mathrm{Fe}_{2} \mathrm{O}_{3}$ by $\mathrm{H}_{2}$ at $450^{\circ} \mathrm{C}$, and possibly to occlusion effects of $\mathrm{CO}$ in the cages. A correlation was found between the cluster size of $\gamma-\mathrm{Fe}_{2} \mathrm{O}_{3}$ (or $\mathrm{Fe}$, in the reduced samples) and the acidity of the mordenite. The mordenite samples with the higher acidity yielded the smaller particle size for the Fe-containing phase.

The saturation magnetization $\left(\sigma_{s}\right)$ of the as-prepared Fe-mordenite samples is plotted in Fig. 3 as a function of the ratio in the mordenite. The $\sigma_{s}$ had the lowest value for the sample with a ratio $=17$.

Thermomagnetic measurements $(\sigma$ vs $T)$ showed a similar trend for all samples. It was seen from these measurements $(\sigma$ vs $T)$ that the magnetization increased to a maximum at $450^{\circ} \mathrm{C}$. This may be ascribed to an agglomeration of clusters from the initial highly dispersed iron oxide phase to a more stable $\gamma-\mathrm{Fe}_{2} \mathrm{O}_{3}{ }^{14}$ with a larger particle size. For sample $\mathrm{D}$ (ratio $=60$ ), $\sigma_{s}$ was found to be $73 \mathrm{emu} / \mathrm{g}$ of $\gamma-\mathrm{Fe}_{2} \mathrm{O}_{3}$ which agrees well with the bulk saturation magnetization for $\gamma-\mathrm{Fe}_{2} \mathrm{O}_{3}$. This $\sigma_{s}$ for sample $\mathrm{D}$ demonstrated that for the sample with lowest acidity, almost all iron clusters had grown to a relatively large (bulk) size, whereas $\sigma_{s}$ for sample $\mathrm{B}$ (ratio $=17$ ) showed $38 \mathrm{emu} / \mathrm{g}$ of $\gamma-\mathrm{Fe}_{2} \mathrm{O}_{3}$, suggesting that

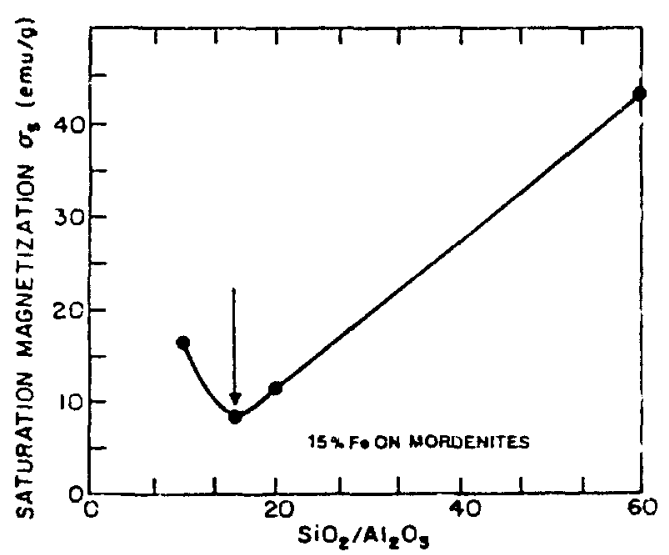

FIG. 3. Saturation magnetization $\left(\sigma_{s}\right)$ vs $\mathrm{SiO}_{2} / \mathrm{Al}_{2} \mathrm{O}_{3}$ ratio. The arrow shows the ratio $=17$, at which the acidity is highest. 


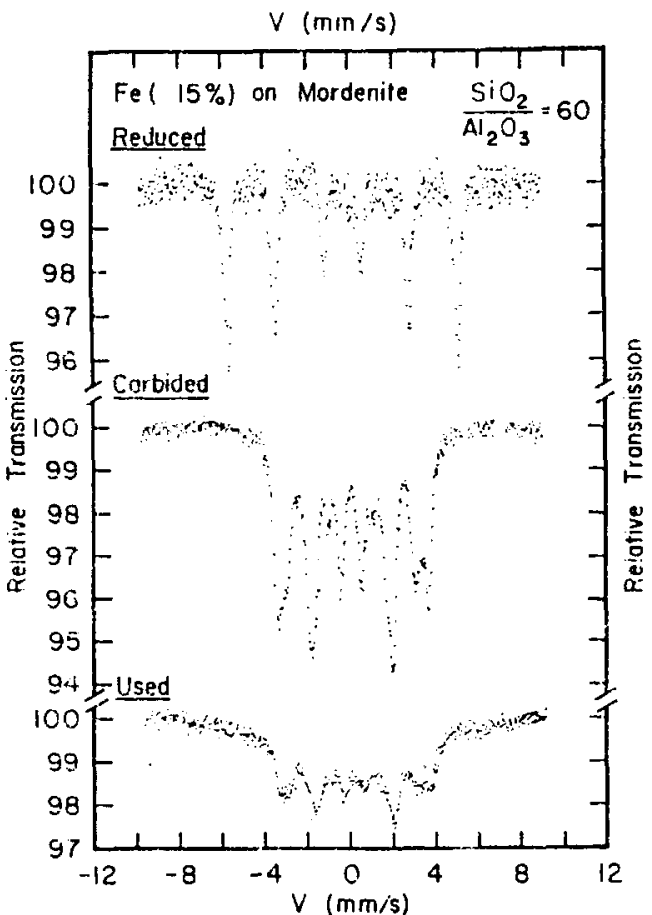

FIG. 4. Room temperature Mössbauer spectra for reduced, carbided, and used sample $\mathrm{D}\left(\mathrm{SiO}_{2} / \mathrm{Al}_{2} \mathrm{O}_{3}=60\right)$.

a large percentage of iron species showed superparamagnetism.

It is seen from the magnetization etc. results that (i) with increasing acid sites in the mordenite framework, a better dispersion of superparamagnetic clusters of Fe oxides is obtained. Furthermore, the highest $\mathrm{Fe}$ dispersion was seen in the mordenite with the largest number of acid sites, ratio $=17$; that (ii) due to high acidity of the mordenite, some $\mathrm{Fe}^{3+}$ ions could penetrate into the pores of mordenites; and (iii) a metal support interaction was observed with increasing acid sites in the mordenite. (cf. Ref. 10)

The Mössbauer spectra of all reduced samples consisted of a six-line pattern corresponding essentially to metallic $\mathrm{Fe}^{0}$. A typical spectrum of the reduced sample (sample $\mathrm{D}$, ratio $=60$ ) is shown in Fig. 4. It was found that this sample was reduced completely in about $2 \mathrm{~h}$, whereas all other samples required longer time for complete reduction. Only the sample $\mathrm{D}($ ratio $=60)$ could be carbided under the conditions mentioned earlier. Figure 4 shows the Mössbauer spectrum of the carbided sample $D$; it consists of superposition of at least four six-line patterns corresponding to two different iron-carbon phases. This complex spectrum was interpreted as arising from $\mathrm{Hägg}$ carbide $\left(\mathrm{Fe}_{5} \mathrm{C}_{2}\right)$ and cementite $\left(\mathrm{Fe}_{3} \mathrm{C}\right)$ in the ratio $80: 20$, respectively, since the former has three inequivalent sites, whereas the latter has only one. ${ }^{15}$

The spectrum of the used sample D recorded after $16 \mathrm{~h}$ of syngas conversion is also shown in Fig. 4. This spectrum indicated the presence of Hägg carbide and cementite in the used sample in the ratio of $60: 40$, respectively. Hence, it was concluded that during the syngas reaction a part of Hägg carbide was converted into cementite (cf. Ref. 16).
The catalytic activity study of the conversion of syngas $\left(\mathrm{CO}+\mathrm{H}_{2}\right)$ over the Fe-mordenite samples with ratios $=12$, 17 , and 60 , additionally confirmed the trends in acidity with varying $\mathrm{SiO}_{2} / \mathrm{Al}_{2} \mathrm{O}_{3}$ ratios mentioned earlier. In this class of catalysts, the acidity of the zeolite leads to the formation of aromatics (alkylbenzenes) which are constituents of high octane gasoline. At a reaction temperature of $280^{\circ} \mathrm{C}$, after the catalysts was on stream for four days, the fraction of aromatics in the liquid hydrocarbon product was 3,17 , and 6 percent, respectively, for the catlysts with ratios $=12,17$, and 60 , respectively. This indicated that the highest acid activity is present in the catalyst with $\left[\mathrm{SiO}_{2} / \mathrm{Al}_{2} \mathrm{O}_{3}\right]$ ratio $=17$.

\section{CONCLUSIONS}

The above results showed the presence of an interaction between $\mathrm{Fe}$ and mordenite in catalysts prepared by impregnation with $\mathrm{Fe}_{3}(\mathrm{CO})_{12}$. The effects of this metal-zeolite interaction were revealed from Mössbauer and magnetic studies. The Fe-mordenite interaction has been shown to influence the cluster size of the Fe-containing species, i.e., the stronger the interaction the higher is the dispersion of Fe. Finally, the strength of the metal-zeolite interaction was correlated with the $\mathrm{SiO}_{2} / \mathrm{Al}_{2} \mathrm{O}_{3}$ ratios in the mordenites in the same manner in which the acidity and the catalytic activity were related to the $\left[\mathrm{SiO}_{2} / \mathrm{Al}_{2} \mathrm{O}_{3}\right]$ ratios.

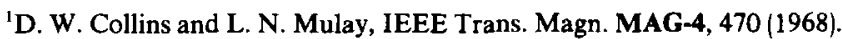
${ }^{2}$ R. T. Obermyer, L. N. Mulay, C. Lo, M. Oskooie-Tabrizi, and V. U. S. Rao, J. Appl. Phys. 53, 2683 (1982).

${ }^{3}$ C. D. Chang, W. H. Lang, and A. J. Silvestri, J. Catal. 56, 268 (1979).

${ }^{4}$ P. D. Caesar, J. A. Brennan, W. E. Garwood, and J. Ciric, J. Catal. 56, 274 (1979).

${ }^{5}$ V. U. S. Rao and R. J. Gormley, Hydrocarbon Process. 59, 139 (1980).

${ }^{6}$ T. J. Huang and W. O. Haag, Am. Chem. Soc. Ser. 152, 308 (1981).

${ }^{7}$ P. M. Koradia, J. R. Kiovsky, and M. Y. Asim, J. Catal. 66, 290 (1980).

${ }^{8}$ S. J. Tauster, S. C. Fung, R. T. K. Baker, and J. A. Horsley, Science 211, 1121 (1981).

${ }^{9} \mathrm{G}$. C. Bond, Metal-Support and Metal-Additive Effects in Catalysis, edited by B. Imelik, et al., (Elsevier, New York 1982), p. 1.

${ }^{10} \mathrm{M}$. Oskooie-Tabrizi, C. Lo, and L. N. Mulay, Proceedings of the Intermagnetics Conference, Philadelphia, April 1983, IEEE Trans. Magn. MAG-19, 2001 (1983).

${ }^{11}$ G. A. Melson, J. E. Crawford, J. W. Grites, K. J. Mbadcam, J. M. Stencel, and V. U. S. Rao, Am. Chem. Soc. Symp. Ser. 218, 397 (1983).

${ }^{12}$ H. Yamamura and L. N. Mulay, J. Appl. Phys. 50, 7795 (1979).

${ }^{13}$ L. N. Mulay, in Physical Methods of Chemistry, edited by A. Weissberger and W. Rossiter (Wiley, New York, 1972), Chap. 7.

${ }^{14} \mathrm{G}$. Bate, in Ferromagnetic Materials, Vol. 2, edited by E. P. Wohlfarth (North-Holland, New York, 1980), Chap. 7.

is J. B. Nagy, M. Van Eenoo, and E. G. Derouane, J. Catal. 58, 230 (1979).

${ }^{16}$ C. Lo, K. R. P. M. Rao, L. N. Mulay, V. U. S. Rao, and R. T. Obermeyer, in Mössbauer Spectroscopy and Its Chemical Applications, edited by J. G. Stevens and G. K. Shenoy, "Advances in Chemical Series," Vol. 194, (Am. Chem. Soc., Washington, D.C., 1981), p. 573. 